\title{
ANALYSIS OF PROCESS OF BEAD SHAPING IN CLADDING ON NARROW SUBSTRATE
}

\author{
K.A. YUSHCHENKO, A.V. YAROVITSYN, G.D. KHRUSHCHOV, A.A. FOMAKIN and Yu.V. OLEJNIK \\ E.O. Paton Electric Welding Institute, NASU
}

11 Bozhenko Str., 03680, Kiev, Ukraine. E-mail: office@paton.kiev.ua

\begin{abstract}
Analysis of geometry dependencies of bead shaping was carried out at full-scale modelling of technologically possible cross-sections of beads deposited on narrow substrate of $0.5-5.0 \mathrm{~mm}$ thickness. The tasks were specified for technological regulation of shape of single-layer bead and series of process criteria was stated, namely efficient rising of narrow substrate being deposited, optimum effective cross-section of the bead and acceptable side machining allowances. Proposed are the formulae for estimation engineering calculations determining the relationship between required height of deposited layer, bead size, mass of deposited metal and filler consumption. 16 Ref., 3 Tables, 9 Figures.
\end{abstract}

Keywords: microplasma powder cladding, nickel heat-resistant alloy, narrow substrate, full-scale modelling of bead cross-section, process criteria of bead shape

Significant scope of works in repair of parts of aircraft gas turbine engines falls at repair or strengthening of their sealing and antivibration elements of $0.5-5.0 \mathrm{~mm}$ width and length from $10-15 \mathrm{~mm}$ to $2-3 \mathrm{~m}$. Argon-arc [1, 2] or microplasma powder cladding [3-5] applying nickel heat-resistant alloys as filler material are used for solving of such tasks. It is carried out under conditions of free bead formation on vertically positioned construction element of part. A bead is formed under effect of gravity force, arc pressure, internal friction of molten metal (toughness) and surface tension in processes of cladding. Its cross-section contour is approximated to circumference or ellipse (Figure 1). A special term «narrow substrate», i.e. elements of surface of base metal, width of which do not exceed weld pool width $[6,7]$, was taken by the E.O. Paton

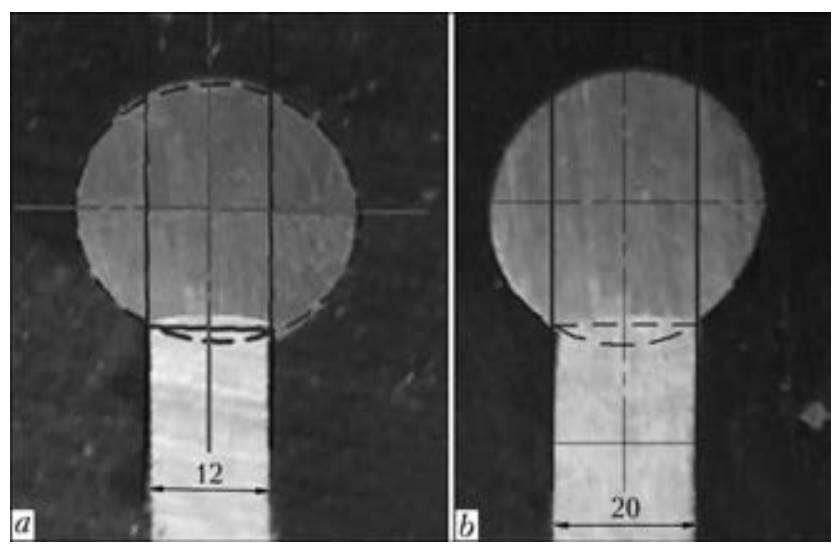

Figure 1. Contour of cross-section of beads deposited on narrow substrate of different width: $a-$ ellipse; $b-$ circumference
Electric Welding Institute for such surfaces being deposited.

Example of three-layer microplasma powder cladding of fragment of tip of blade airfoil ( $\mathrm{Fi}^{-}$ gure 2) was used for expansion of concept on geometry and process dependencies in formation of narrow bead-on-plate for nickel heat-resistance alloys with limited weldability [8, 9]. Analysis of modes of cladding carried on procedure from work [10] shows that growth of cross-section size of deposited bead from JS32 alloy of 2-4 mm range at limited change of welding current (1$3 \mathrm{~A})$ is accompanied by significant increase of heat input. In turn, more than 2 times increase of heat energy input during arc burning promotes for formation of microcracks in the deposited metal at further heat treatment based on homogenizing mode for JS26 and JS32 alloys.

In should be noted that mechanism of technological regulation of cross-section of deposited metal in cladding of $0.5-5.0 \mathrm{~mm}$ width narrow substrate is fragmentary studied $[2,3,11]$. Therefore, in order to form corresponding representations of aims and tasks of such regulation, it is initially reasonable to analyze predicted shape of deposited beads in the range of their relative width $B / \delta=1-10$ and relative height $H / \delta \leq 4$. These indices characterize a set of sizes of bead cross-sections, which can be kept on considered narrow substrate without application of forming devices in process of microplasma and argon-arc cladding. Taking into account mentioned above the aim of the present work is:

- analysis of dependencies of distribution of deposited and base metal in possible bead crosssections and formation of generalized criteria of their shape optimality, and 


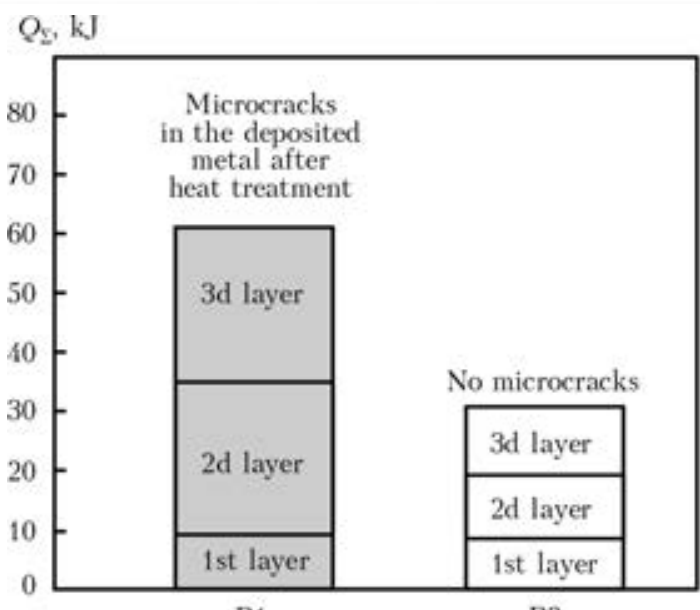

B1

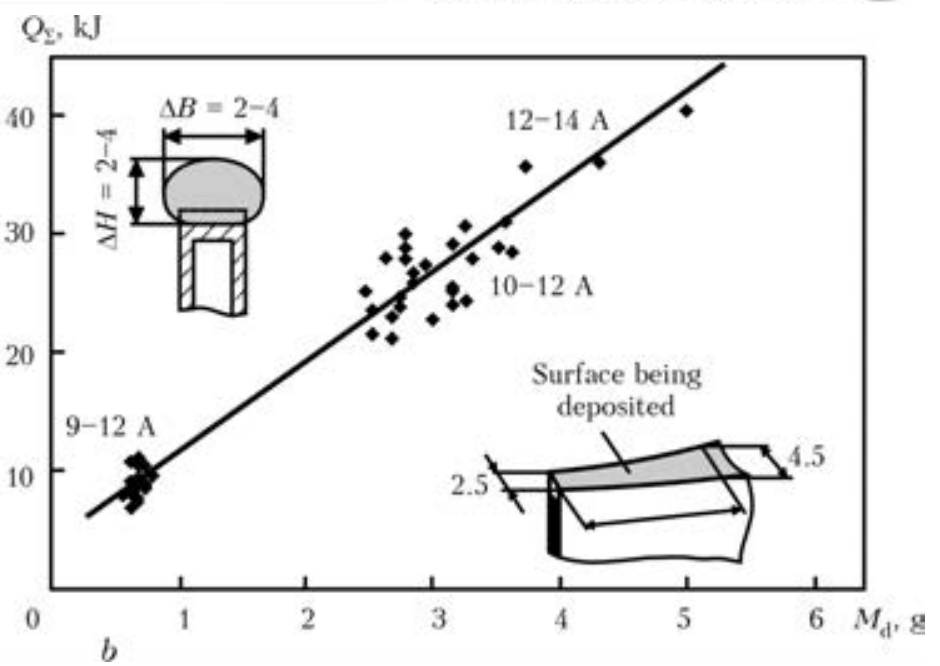

a

Figure 2. Tendency to microcrack formation in deposited metal JS32 at 3-layer microplasma powder cladding of tip of blade airfoil $(a)$, and dependence of total heat input in anode $Q_{\Sigma}$ on mass $M_{\mathrm{d}}$ of bead deposited per one layer $(b)$

- deriving of engineering dependencies to determine the relationship between the necessary height of deposited layer, bead size, mass of deposited metal and filler consumption, required for corresponding repair-reconstruction technologies.

Figure 3 and Table 1 give initial geometry indices of bead deposited on narrow substrate necessary for further analysis of its shape. Authors of the paper tried to approximate definitions of the most of them to ones traditionally accepted for bead-on-plate $[12,13]$. Series of new definitions, i.e. effective bead height $h$, bead cross-section $F_{\mathrm{E}}$, cross-section of deposited metal in bead $F_{\mathrm{DP}}$, were implemented due to the necessity of study of size of rectangle with sides $\delta$ and $\left(h+h_{\mathrm{BM}}\right)$ inscribed in bead contour. The following assumptions were taken in analysis of bead cross-section (see Figure 3):

- bead contour is the part of circumference or ellipse;

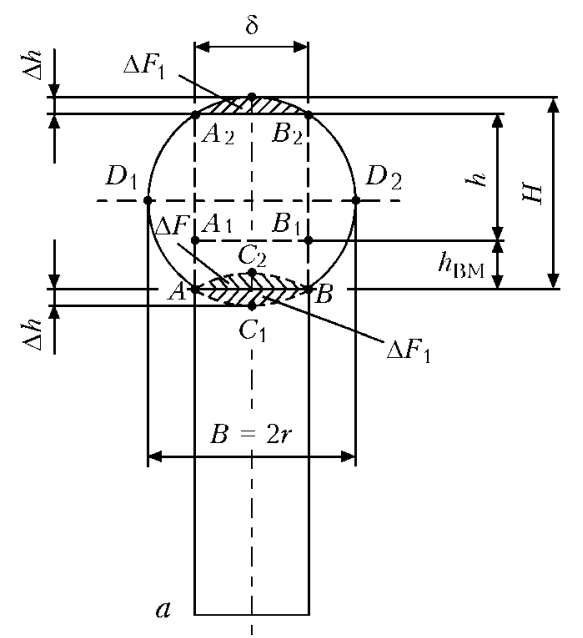

- fusion line of base and deposited metals lies in $A B$ segment;

- areas of corresponding ellipse or circumference and contour of bead cross-section differ per $\Delta F_{1}$ segment value, which equals the area of bead upper reinforcement;

- molten base metal does not come out of the limits of narrow substrate and being localized in rectangle with $\delta$ and $h_{\mathrm{BM}}$ sides;

- after machining deposited metal has rectangular cross-section with $\delta$ and $h_{\mathrm{BM}}+h$ sides.

Shape of beads was studied by means of fullscale modelling of technologically possible crosssections at variation of $\delta, H, B$ parameters and determination of areas of its constituents ( $\mathrm{Fi}$ gure 4) in the program of system for automatic computer-aided design of process documents Compass-3D V12. The following most probable laws of sequential change of geometric configuration corresponding to bead contour were considered: diameter of circumference increases ( $\mathrm{Fi}$ gure $5, a$ ), horizontal axis of ellipse expands up

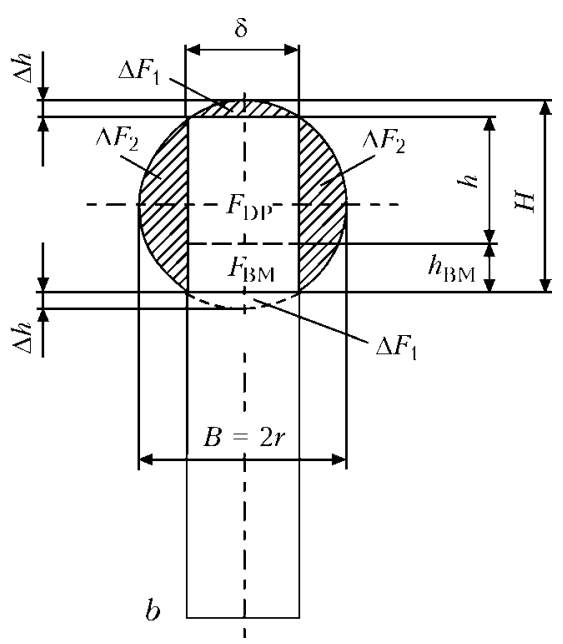

Figure 3. Basic indices of bead cross-section in single-layer cladding on narrow substrate (a) (designations see in Table 1), and (parts of the bead $(b)$ removed in machining of deposited metal) (hatched) 
SCIENTIFIC AND TECHNICAL

Table 1. Main geometry indices of cross-section of bead deposited on narrow substrate

\begin{tabular}{|c|c|c|}
\hline No. & Parameter & Designations according to Figure 3 \\
\hline \multicolumn{3}{|c|}{ 1. Size } \\
\hline 1.1 & Width of narrow substrate & $\delta$ \\
\hline 1.2 & Bead width & $B$ \\
\hline 1.3 & Bead height & $H$ \\
\hline 1.4 & Depth of base metal penetration & $h_{\mathrm{BM}}$ \\
\hline 1.5 & Effective height of deposited metal & $h$ \\
\hline 1.6 & Effective height of bead & $h_{\mathrm{BM}}+h$ \\
\hline 1.7 & Thickness of bead side reinforcement & $\Delta p=0.5(B-\delta)$ \\
\hline 1.8 & Height of bead upper reinforcement & $\Delta h=H-h-h_{\mathrm{BM}}$ \\
\hline \multicolumn{3}{|c|}{ 2. Relative size } \\
\hline 2.1 & Relative width of bead & $B / \delta$ \\
\hline 2.2 & Relative height of bead & $H / \delta$ \\
\hline 2.3 & Relative depth of base metal penetration & $h_{\mathrm{BM}} /\left(h_{\mathrm{BM}}+h\right)$ \\
\hline 2.4 & Relative height of bead upper reinforcement & $\Delta h /(H+\Delta h)$ \\
\hline \multicolumn{3}{|c|}{ 3. Contour } \\
\hline 3.1 & Geometry figure corresponding to bead contour & Closed $A C_{1} B D_{2} C D_{1}$ curve \\
\hline 3.2 & Perimeter of bead contour & Closed $A B D_{2} C D_{1}$ curve \\
\hline \multicolumn{3}{|c|}{ 4. Cross-section area } \\
\hline 4.1 & Area of base metal penetration & $F_{\mathrm{BM}}=h_{\mathrm{BM}} \delta$ \\
\hline 4.2 & Effective area of deposited metal in bead & $F_{\mathrm{DP}}=h \delta$ \\
\hline 4.3 & Effective bead section & $F_{\mathrm{E}}=F_{\mathrm{BM}}+F_{\mathrm{DP}}$ \\
\hline 4.4 & Area of bead upper reinforcement & Segment $\Delta F_{1}$ \\
\hline 4.5 & Area of bead side reinforcement & Segment $\Delta F_{2}$ \\
\hline 4.6 & Area of deposited bead (limited by perimeter of bead contour) & $F_{\mathrm{B}}=F_{\mathrm{E}}+\Delta F_{1}+2 \Delta F_{2}$ \\
\hline 4.7 & Area of geometry figure corresponding to bead contour & $F_{\mathrm{BCF}}=F_{\mathrm{E}}+2 \Delta F_{1}+2 \Delta F_{2}$ \\
\hline \multicolumn{3}{|c|}{ 5. Relationship of areas of elements in bead cross-section } \\
\hline 5.1 & Portion of base metal & $\gamma_{\mathrm{BM}}=F_{\mathrm{BM}} / F_{\mathrm{B}}$ \\
\hline 5.2 & Relative area of bead effective section & $\gamma_{\mathrm{E}}=F_{\mathrm{E}} / F_{\mathrm{B}}$ \\
\hline 5.3 & Relative area of effective section of deposited metal & $\gamma_{\mathrm{ED}}=F_{\mathrm{DP}} / F_{\mathrm{B}}$ \\
\hline
\end{tabular}

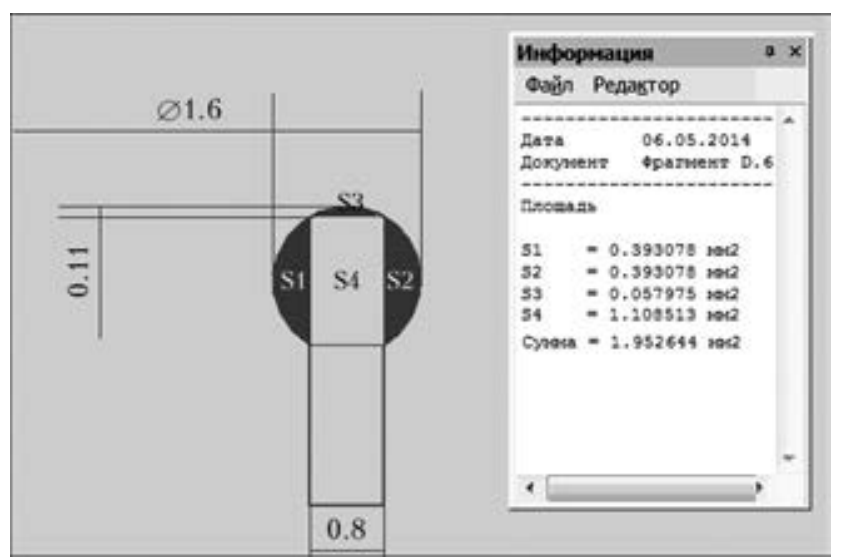

Figure 4. Example of determination of area of bead crosssection elements at their full-scale modelling in system of automated computer-aided design Compass-3D V12 to circumference (Figure 5, b), and vertical axis of ellipse stretches up to circumference ( $\mathrm{Fi}^{-}$ gure $5, c)$.

Initially, full-scale modelling of technologically possible shapes of cross-section of singlelayer deposited metal was carried out for narrow substrate of $\delta=0.8,1.5,4$ and $6 \mathrm{~mm}$ in the ranges of bead width-to-height relationship of $B=(1-$ $10) \delta$ and $H \leq 4 \delta$. Amount of analyzed cross-sections made 40-50 pcs for each dimension type of width of narrow substrate. Obtained data array $\gamma_{\mathrm{E}}$ and $B / \delta$ was estimated on membership to general dependence $\gamma_{\mathrm{E}}=f\left(B / \delta ; \gamma_{\mathrm{BM}}=0\right)$ visually as well as using statistical criteria* [14], namely

\footnotetext{
${ }^{*}$ At $\gamma_{\mathrm{E}}=f(B / \delta)$ division for series of linear sections.
} 
Pearson $(R)$, index of determination $\left(R^{2}\right)$ and Fischer $(F)$.

After that, determined geometry dependencies of bead shape were cross-checked for $\delta=0.5,2$, $3,5,8$ and $10 \mathrm{~mm}$ by means of random sampling of bead width-to-height relationship in the same range. Amount of analyzed possible cross-sections made $10-15$ pcs for each additional dimension type of narrow substrate width.

Figure 6 shows collection of $\gamma_{\mathrm{DP}}=f(B / \delta$; $\gamma_{\mathrm{BM}}$ ) dependencies obtained as a result of processing of data of full-scale modelling of technologically possible cross-sections of deposited beads. $\gamma_{\mathrm{ED}}<0$ case corresponds to lowering of narrow substrate relatively to its initial level $Z_{1} Z_{2}, \gamma_{\mathrm{ED}}>0-$ to rising. Approximation of aggregate of points $B / \delta$ and $\gamma_{\mathrm{BM}}$ by power function at which $\gamma_{\mathrm{ED}}=0$ at $B / \delta>1.4$ allowed connecting condition of narrow substrate rising with one of the most important indices of cladding efficiency, i.e. portion of base metal in the deposited bead:

$$
\gamma_{\mathrm{BM}}<\gamma_{\mathrm{E}}=\left(\frac{B}{\delta}\right)^{-0.866} \text {. }
$$

Thus, increase of rising efficiency of narrow substrate being deposited with expansion of relative bead width requires more rigid limitation of portion of base metal in it. It should also be noted that maximum $\gamma_{\mathrm{E}}=0.714$ values (see curve 1 in Figure 6 ) is observed for $B / \delta=1.28$, and relative area of upper and side bead reinforcements is minimum at that. Beads with $B / \delta=1.2-1.4$, for which $\gamma_{\mathrm{E}}>0.7$, can be assumed at some approximation as corresponding to criterion of maximum
SCIENTIFIC AND TECHNICAL
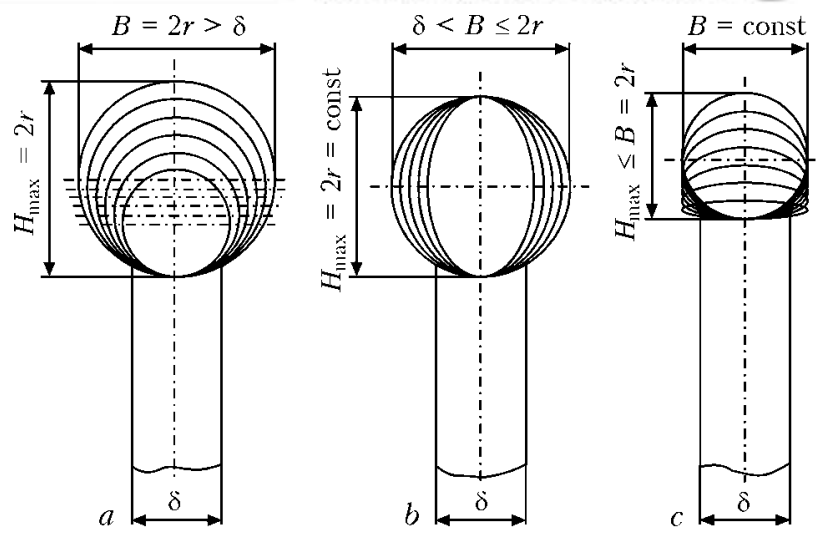

Figure 5. Typical changes of shape of bead cross-section at variation of parameters of mode of narrow substrate cladding

of effective cross-section area. For $B / \delta=1.4-10$, $\gamma_{\mathrm{E}}$ value in $0.12-0.70$ value range can be specified with the help of dependence (1).

Preliminary specification of portion of base metal is necessary for analysis of peculiarities of metal distribution between central part and periphery of the bead. Content of deposited $\gamma_{\mathrm{ED}}$ and base metal $\gamma_{\mathrm{BM}}$ in the central part of the bead is, respectively:

$$
\begin{gathered}
\gamma_{\mathrm{ED}}=\gamma_{\mathrm{E}}-\gamma_{\mathrm{BM}}, \\
\gamma_{\mathrm{BM}}=\frac{F_{\mathrm{BM}}}{F_{\mathrm{B}}}=\frac{h_{\mathrm{BM}} \delta}{F_{\mathrm{B}}},
\end{gathered}
$$

where, in the cross-section of deposited bead $h_{\mathrm{BM}}$, $F_{\mathrm{BM}}$ are the depth and area of base metal penetration, and $F_{\mathrm{B}}$ is the bead area. $F_{\mathrm{B}}$ value can be calculated as

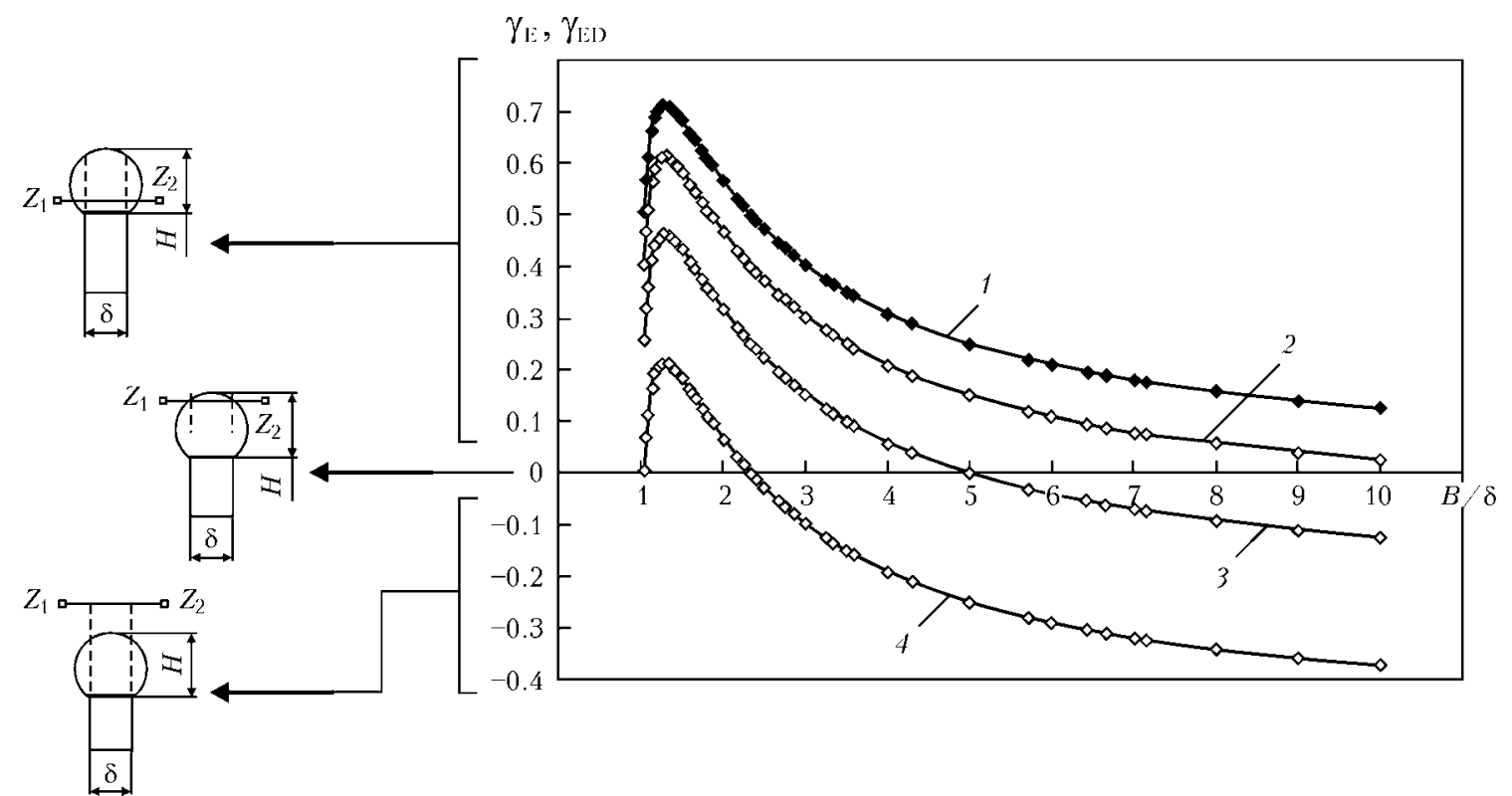

Figure 6. Dependence of relative area of effective bead section $\gamma_{E}$ and relative area of effective section of deposited metal $\gamma_{\mathrm{ED}}$ on relative width of bead $B / \delta$ (based on data of statistical processing of full-scale modelling results): $Z_{1}, Z_{2}-$ level of narrow substrate before bead deposition; $1-\gamma_{\mathrm{E}}=\gamma_{\mathrm{ED}}$ at $\gamma_{\mathrm{BM}}=0 ; 2-\gamma_{\mathrm{ED}}$ at $\gamma_{\mathrm{BM}}=0.1 ; 3-$ at $\gamma_{\mathrm{BM}}=0.25$; $4-$ at $\gamma_{\mathrm{BM}}=0.5$ 
SCIENTIFIC AND TECHNICAL
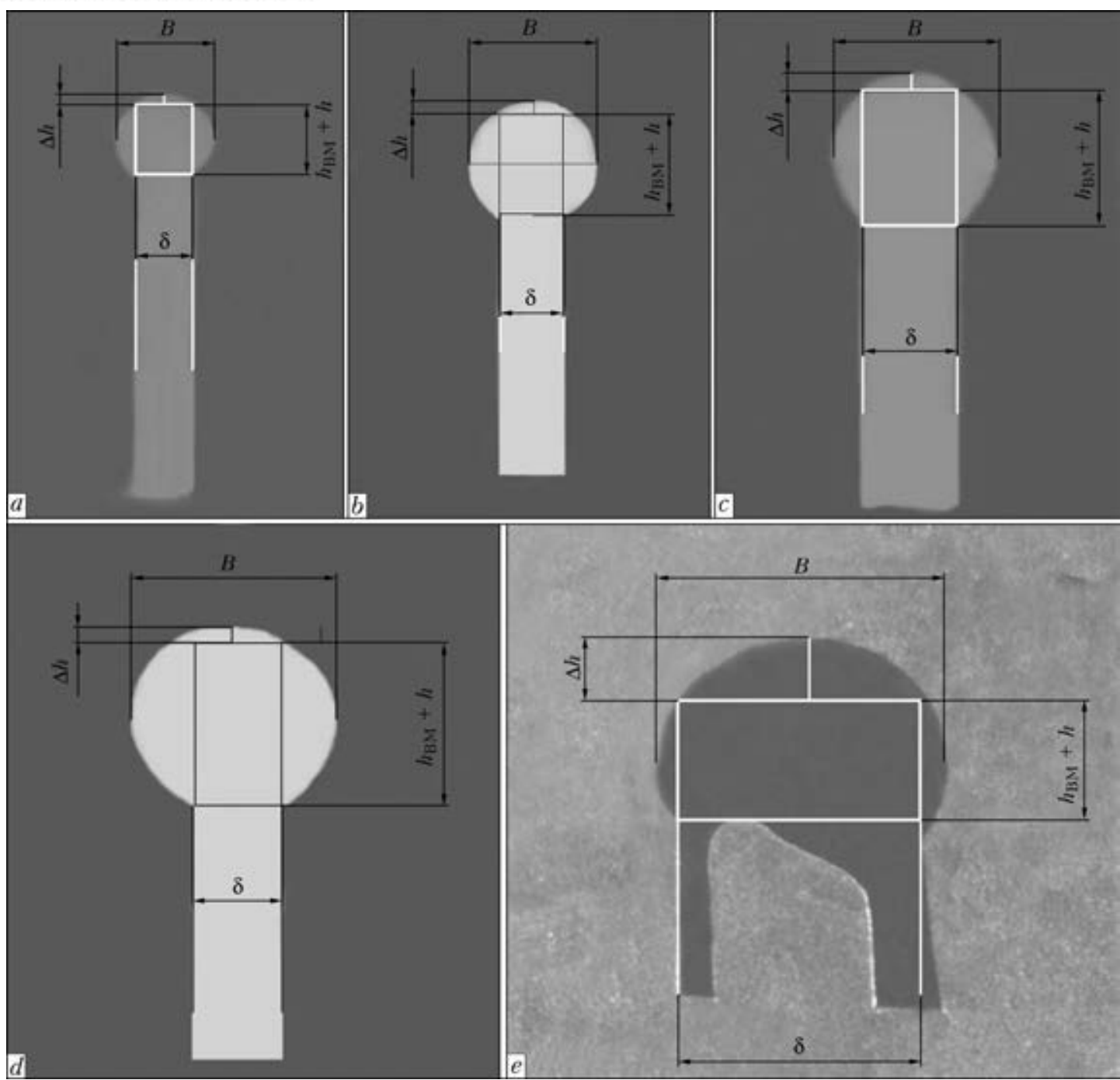

Figure 7. Scheme of measurements of sizes and view of cross-section contours of beads deposited on narrow substrate of different width (according to Table 2)

$$
F_{\mathrm{B}}=F_{\mathrm{BCF}}-\Delta F_{1}=0.25 \pi B\left(h_{\mathrm{BM}}+h\right)-\Delta F_{1},
$$

where $F_{\mathrm{BCF}}$ is the area limited by figure of contour of bead cross-section (ellipse or circumference); $\Delta h, \Delta F_{1}$ are the value and area of bead upper reinforcement, respectively. In turn, $\Delta F_{1}$ value of circumference segment area (or in general case - ellipse) can be approximately calculated similar to area of upper reinforcement of butt weld [13]:

$$
\Delta F_{1}=0.73 \Delta h \delta .
$$

Value of upper reinforcement of deposited bead $\Delta h$, which combines necessary height of deposited layer with necessary bead height, is to be determined for calculations on dependencies (1)-(5). Formulae for calculation of saggita of segment [15] can be used for figures in form of circumference, corresponding to bead contour, however, accurate calculation of $\Delta h$ for figure in form of ellipse is complicated.

Processing of statistical data of full-scale modeling showed that given parameter can have the

\begin{tabular}{|c|c|c|c|c|c|c|c|c|c|c|}
\hline \multirow{3}{*}{ Parameter } & \multicolumn{2}{|c|}{ Figure $7, a$} & \multicolumn{2}{|c|}{ Figure $7, b$} & \multicolumn{2}{|c|}{ Figure $7, c$} & \multicolumn{2}{|c|}{ Figure $7, d$} & \multicolumn{2}{|c|}{ Figure $7, e$} \\
\hline & \multicolumn{2}{|c|}{$\Delta=1.2 \mathrm{~mm}$} & \multicolumn{2}{|c|}{$\Delta=1.2 \mathrm{~mm}$} & \multicolumn{2}{|c|}{$\Delta=2.0 \mathrm{~mm}$} & \multicolumn{2}{|c|}{$\Delta=2.0 \mathrm{~mm}$} & \multicolumn{2}{|c|}{$\Delta=5.0 \mathrm{~mm}$} \\
\hline & Calc. & Actual & Calc. & Actual & Calc. & Actual & Calc. & Actual & Calc. & Actual \\
\hline$B, \mathrm{~mm}$ & - & 2 & - & 2.40 & - & 3.32 & - & 4.52 & - & 6 \\
\hline$B / \delta$ & 1.67 & - & 2 & - & 1.66 & - & 2.26 & - & 1.20 & - \\
\hline$h_{\mathrm{BM}}+h, \mathrm{~mm}$ & - & 1.49 & - & 1.95 & - & 2.66 & - & 3.57 & - & 2.77 \\
\hline$\Delta h, \mathrm{~mm}$ & 0.20 & 0.23 & 0.16 & 0.20 & 0.36 & 0.43 & 0.30 & 0.22 & 1.06 & 1.20 \\
\hline
\end{tabular}

Table 2. Comparison of calculation and actual value of bead upper reinforcement $\Delta h$ deposited on narrow substrate of different width 
most reasonable expression via relative height of bead upper reinforcement $\Delta h /(H+\Delta h)$. Indicted dependence is approximated to power function with high degree of certainty

$$
\frac{\Delta h}{H+\Delta h}=0.3215\left(\frac{B}{\delta}\right)^{-2.161} \text {. }
$$

Taking into account that $H=h_{\mathrm{BM}}+h+\Delta h$, the following expression for upper reinforcement of the deposited bead is received after series of transformations:

$$
\Delta h=\frac{0.3215\left(\frac{B}{\delta}\right)^{-2.161}\left(h_{\mathrm{BM}}+h\right)}{1-0.6430\left(\frac{B}{\delta}\right)^{-2.161}} .
$$

Numerical modelling data based on dependence (7) indicate that the value of bead upper reinforcement does not exceed $1 \mathrm{~mm}$. $\Delta h$ value can make several millimeters in the case of combination of $B / \delta>2$ and $h_{\mathrm{BM}}+h>3-5 \mathrm{~mm}$ that should be taken into account in selection of size of the deposited bead. It is determined (Figure 7, Table 2) that acceptable level of convergence of calculation (7) and experimental data is achieved for height of bead upper reinforcement $\Delta h$.

Substitution of expressions (4), (5), (7) in dependence (3) and some transformations provide for the following expression of portion of base metal $\gamma_{\mathrm{BM}}$ through relative penetration depth of base metal $h_{\mathrm{BM}} /\left(h_{\mathrm{BM}}+h\right)$ and relative bead width $B / \delta$ :

$$
\begin{gathered}
\gamma_{\mathrm{BM}}=\frac{h_{\mathrm{BM}}}{h_{\mathrm{BM}}+h} \times \\
\times \frac{\left[1-0.6430\left(\frac{B}{\delta}\right)^{-2.161}\right.}{0.25 \pi\left(\frac{B}{\delta}\right)^{-2.161}-0.2347\left(\frac{B}{\delta}\right)^{-2.161}} .
\end{gathered}
$$

Let us plot dependencies (1), (2), (8) on one diagram and estimate distribution of metal between effective bead section and its reinforcements at relative bead width more than 1.4 ( $\mathrm{Fi}^{-}$ gure 8). Numerical modeling data show that content of base metal in the bead can make 2-22\% in area of optimum modes of cladding $\left(h_{\mathrm{BM}} /\left(h_{\mathrm{BM}}+h\right)=0.1-0.3\right)$. Efficiency of filling of bead central part by molten metal is sequentially reduced due to increase of area of side allowances at rise of $B / \delta$ relationship.

Due to the fact that portion of base metal in the deposited bead is limited, it is reasonable to extend concept of dependencies of consumption

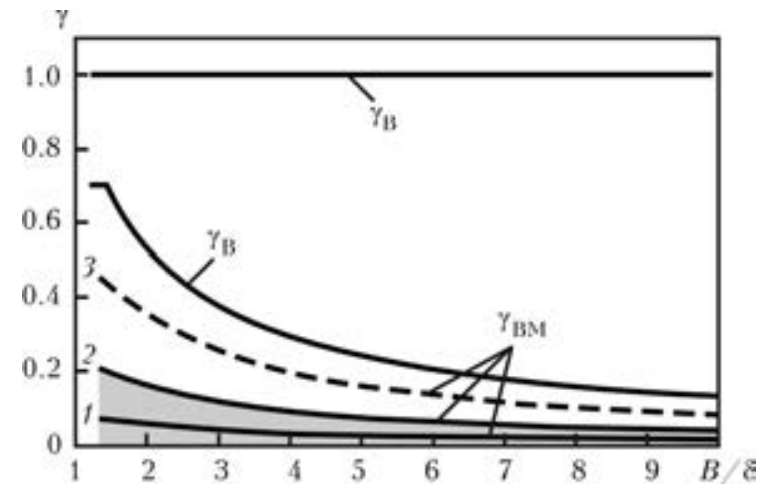

Figure 8. Balance of metal distribution in deposited bead depending on relative bead width: $\gamma_{\mathrm{B}}-$ whole metal; $\gamma_{\mathrm{E}}-$ portion of metal in bead effective section; $\gamma_{\mathrm{BM}}-$ portion of base metal corresponding to values of relative depth of penetration; $1-h_{\mathrm{BM}} /\left(h+h_{\mathrm{BM}}\right)=0.1 ; 2-0.33 ; 3-$ 0.66 (area of filling corresponds to optimum cladding modes)

of filler metal in narrow substrate cladding. They are determined by direct and indirect filler loss.

The first type of loss is mainly provoked by distributed feed of disperse filler in the weld pool $[3,16]$. The second one is due to «redistribution» of deposited metal from rectangle with $\delta$ and $\left(h+h_{\mathrm{BM}}\right)$ sides in area of upper and side reinforcements (see Figures 1 and 3). Limitation of cross-section areas $\Delta F_{1}$ and $\Delta F_{2}$ in the deposited bead is one of the important technological tasks for such type of deposition due to appropriateness of reduction of consumption of arc heat and costs on expensive filler for cladding of «excess» bead volume which is subsequently removed by machining.

The production practice showed that $\Delta p=$ $=0.50-1.25 \mathrm{~mm}$ thickness range of bead side reinforcement corresponds to optimum labor expenditures of further treatment. Verification of correspondence of criteria of optimum effective cross-section and optimum labor expenditures directed on treatment of bead deposited over $\delta=$ $=0.5-10 \mathrm{~mm}$ narrow substrate is represented in form of numerical solution (Table 3) of system of equations:

Table 3. Change of relative width of bead $B / \delta$ depending on width of narrow substrate $\delta$ at thickness of bead side reinforcement $\Delta p=0.50-1.25 \mathrm{~mm}$

\begin{tabular}{||c|c|c|c||}
\hline$\delta, \mathrm{mm}$ & $B / \delta$ & $\delta, \mathrm{mm}$ & $B / \delta$ \\
\hline 0.5 & $3-6$ & 5 & $1.20-1.50$ \\
\hline 1.0 & $2-3.50$ & 6 & $1.17-1.42$ \\
\hline 1.5 & $1.67-2.67$ & 7 & $1.14-1.35$ \\
\hline 2.0 & $1.50-2.25$ & 8 & $1.13-1.31$ \\
\hline 2.5 & $1.40-2$ & 9 & $1.11-1.28$ \\
\hline 3.5 & $1.28-1.71$ & 10 & $1.10-1.25$ \\
\hline
\end{tabular}



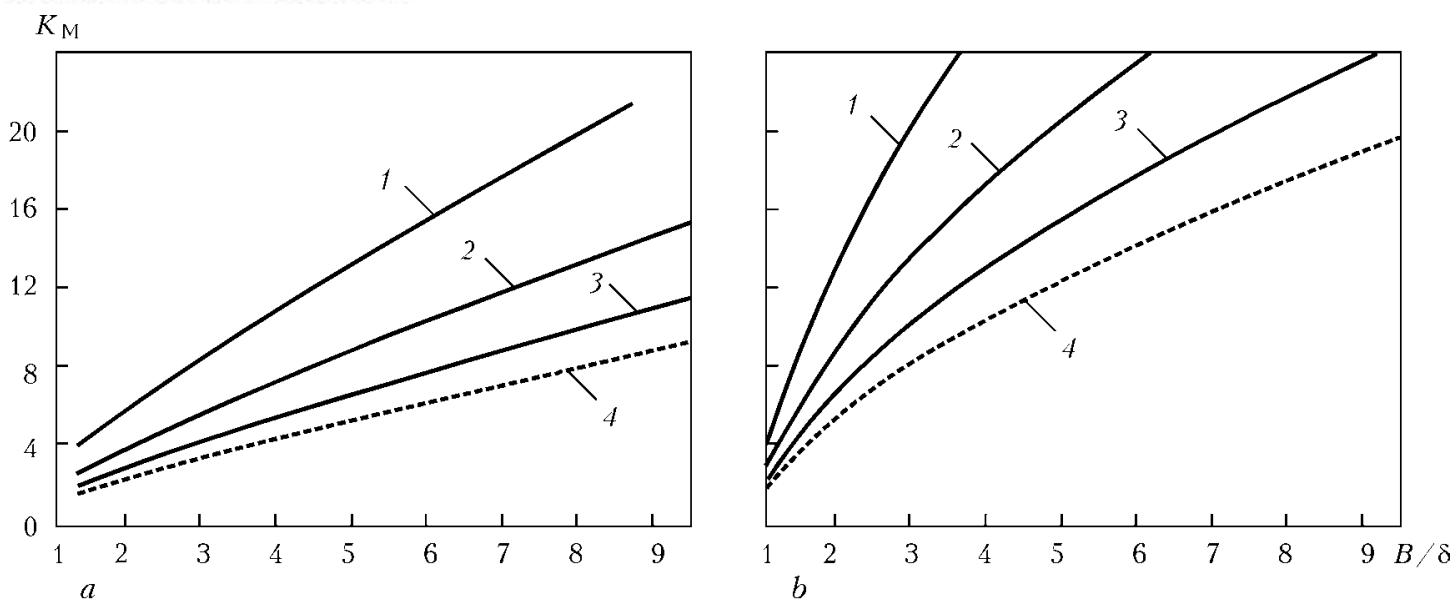

Figure 9. Numerical modelling of coefficient of filler specific consumption $K_{\mathrm{M}}$ depending on relative width of bead and relative depth of penetration: $a-h_{\mathrm{BM}} /\left(h+h_{\mathrm{BM}}\right)=0.25 ; b-0.66$ at $\mathrm{CFU}=0.4(1), 0.6$ (2), 0.8 (3) and 1.0 (4)

$$
\begin{gathered}
\frac{B}{\delta}=\frac{\delta+2 \Delta p}{\delta} \\
1.2 \leq B / \delta \leq 1.4 .
\end{gathered}
$$

It is well known fact that mass of deposited metal $M_{\mathrm{D}}$ can be determined based on cross-section area of deposited metal $F_{\mathrm{D}}$, bead length $L$ and material density $\rho_{\mathrm{M}}$ :

$$
M_{\mathrm{D}}=F_{\mathrm{D}} L \rho_{\mathrm{M}}
$$

Here

$$
F_{\mathrm{D}}=F_{\mathrm{B}}-F_{\mathrm{BM}}=F_{\mathrm{B}}-h_{\mathrm{BM}} \delta .
$$

In turn, $F_{\mathrm{B}}$ area can be expressed through relative effective cross-section of bead $\gamma_{E}$ :

$$
F_{\mathrm{B}}=\frac{F_{\mathrm{E}}}{\gamma_{\mathrm{E}}}=\frac{\left(h_{\mathrm{BM}}+h\right) \delta}{\gamma_{\mathrm{E}}} .
$$

Taking into account (1) the following is received after some transformations:

$$
F_{\mathrm{B}}=(h \mathrm{BM}+h) \delta(B / \delta)^{0.866} .
$$

Dependencies (11)-(14) allow estimating necessary mass of deposited metal for narrow substrate depending on required effective height of deposited metal $h$. A coefficient of specific consumption $K_{\mathrm{M}}$, calculated considering dependencies (2) and (8), is appropriate for demonstration of dynamics of consumption of filler material in its reconstruction. It characterizes increase of total amount of filler in comparison with consumed for filling of bead central part:

$$
\begin{gathered}
K_{\mathrm{M}}=\mathrm{CFU}^{-1}\left(\gamma_{\mathrm{ED}}\right)^{-1} ; \\
M_{N}=K_{\mathrm{M}} M_{0} N,
\end{gathered}
$$

where CFU is the coefficient of filler use; $M_{0}$ is its consumption for rectangle with $\delta$ and $h$ sides in one part; $N$ is the amount of parts recovered by cladding. The results of numerical modelling of $K_{\mathrm{M}}$ value (Figure 9) show significant dependence of filler consumption on width of narrow substrate, coefficient of filler use, relative width of bead and relative depth of penetration of base metal. Figure 9 also shows an appropriateness of development and realizing of additional block of process activities directed on rise of efficiency of disperse filler application (for microplasma powder cladding).

Thus, it is determined that generalized geometry criterion of shape of studied beads is their relative width. Its value of $1.2-1.4$ provides for the maximum relationship of areas of central part and total bead cross-section area, namely approximately 0.7 . The condition of rise of narrow substrate in process of single layer cladding is related with limitation of portion of base metal in the bead $\gamma_{\mathrm{BM}}<\gamma_{\mathrm{E}}=(B / \delta)^{-0.866}$. Portion of base metal for optimum cladding modes and depending on relative bead width should make 3$22 \%$ of total bead volume. The possibility of combination of criteria of optimum bead shape and optimum machining allowance 0.50$1.25 \mathrm{~mm}$ depend on width of narrow substrate and can be complete for $\delta=5-7 \mathrm{~mm}$ and partial for $2.5 \leq \delta<5.0 \mathrm{~mm}$. Only sequential approximation to optimum distribution of metal between bead central part and its reinforcements is possible in the case of $\delta<2.5 \mathrm{~mm}$ narrow substrate at indicated machining allowance.

Obtained data on dependencies of shaping of cross-section of deposited metal and necessary filler consumption also indicate that optimizing the width of bead deposited on narrow substrate allows $10-40 \%$ reduction of amount of «excess» deposited metal and, respectively, decrease amount of irrational heat input to the anode. This will have positive effect on weldability of 
nickel heat-resistant alloys in cladding (particularly, multi-layer) on narrow substrate as well as allow significant limitation of consumption of filler material and labor expenditures of given repair-reconstruction technology.

\section{Conclusions}

Analysis is given to geometry dependencies of shaping of single layer bead on narrow substrate of $0.5-5.0 \mathrm{~mm}$ width and tasks are specified for process regulation of its shape during cladding in part concerning effective rising of narrow substrate, optimum effective cross-section area of the bead and acceptable side machining allowances.

Proposed are the formulae for estimation engineer calculations determining the relationship between required height of deposited layer, bead size, mass of deposited metal and filler consumption in narrow substrate cladding. They can be used in development of repair-reconstruction technologies for parts of aircraft gas-turbine engines.

1. Peremilovsky, I.A., Gejchenko, V.S., Frumin, I.I. (1976) Repair surfacing of aircraft engine turbine blades. Avtomatich. Svarka, 5, 54-56.

2. Arzhakin, A.N., Stolyarov, I.I., Turov, A.V. (2003) Development of technology for repair of 8th stage blades of aircraft engine using automatic surfacing method. Svarshchik, 4, 8-9.

3. Yarovitsyn, A.V., Yushchenko, K.A., Nakonechny, A.A. et al. (2009) Peculiarities of low-amperage argon-arc and microplasma powder cladding on narrow substrate. The Paton Welding J., 6, 31-35.

4. (2010) Technological Seminar of Deloro Stellite in Zaporozhie. Ibid., 1, 46-49.
5. Yushchenko, K.A., Savchenko, V.S., Yarovitsyn, A.V. et al. (2010) Development of the technology for repair microplasma powder cladding of flange platform faces of aircraft engine high-pressure turbine blades. Ibid., 8, 21-24.

6. Som, A.I., Gladky, P.V. (1984) Peculiarities of plasma cladding on narrow substrate. In: New processes of surfacing, properties of deposited metal and transition zone, 20-24. Kiev: Naukova Dumka.

7. Gladky, P.V., Pereplyotchikov, E.F., Ryabtsev, I.A. (2007) Plasma cladding. Kiev: Ekotekhnologiya.

8. Sorokin, L.I. (1997) Weldability of heat-resistant alloys used in aircraft gas-turbine engines. Svarochn. Proizvodstvo, 4, 4-11.

9. Sorokin, L.I. (1999) Stresses and cracks in welding and heat treatment of heat-resistant nickel alloys. Ibid., 12, 11-17.

10. Yarovitsyn, A.V. (2015) Energy approach in analysis of microplasma powder surfacing modes. The Paton Welding J., 5/6, 14-21.

11. Gejkin, V.A., Martyshin, G.V., Sharonova, N.I. et al. (2011) About displacement of deposited bead in repair of labirynth sealings by nonconsumable-electrode gas-shielded surfacing. Svarochn. Proizvodstvo, 3, 27-30.

12. Petrov, G.L., Tumarev, A.S. (1967) Theory of welding processes (with basics of physical chemistry). Moscow: Vysshaya Shkola.

13. Akulov, A.I., Belchuk, G.A., Demiantsevich, V.P. (1977) Technology and equipment of fusion welding. Moscow: Mashinostroenie.

14. Rozanov, Yu.A. (1989) Theory of probability, random processes and mathematical statistics: Manual for higher school students. 2nd ed. Moscow: Nauka.

15. Bronshtejn, I.N., Semendyaev, K.A. (1967) Handbook on mathematics for engineers and higher school students. 11th ed. Moscow: Nauka.

16. Yushchenko, K.A., Yarovitsyn, A.V., Yakovchuk, D.B. et al. (2013) Some techniques for reducing filler powder losses in microplasma cladding. The $\mathrm{Pa}^{-}$ ton Welding J., 9, 30-36.

Received 16.04.2015 